\title{
TREE PLANTER ATTACHMENTS FOR CHEMICAL TREATMENT OF CONIFEROUS SEEDLINGS ${ }^{1}$
}

\author{
By W. G. H. IVES and G. L. WARREN 2
}

\begin{abstract}
White grubs are a serious problem in some of the areas being planted in the reforestation program in Manitoba. Various insecticides have been shown to be effective in the U.S.A., but accurate methods for spot-treatment of seedlings have been lacking. This paper describes attachments which were fitted to a Lowther tree-planter to automatically dispense liquid or granular insecticides beneath coniferous seedlings during planting. Initial trials have shown that the attachments perform satisfactorily under field conditions. Liquid insecticide and granular fertilizer can be delivered simultaneously if desired.
\end{abstract}

\section{INTRODUCTION}

In 1956 the Manitoba Forest Service began an extensive reforestation program in the Belair, Agassiz, Sandilands, and Whiteshell Forest reserves of southeastern Manitoba. Planting of conifers began at the rate of 1,000 acres annually to be increased to 10,000 acres annually by 1970 . Species planted are chiefly: red pine, Pinus resinosa Ait., jack pine, Pinus banksiana Lamb., with some white pine, Pinus strobus L. and white spruce, Picea glauca (Moench) Voss.

Heavy seedling mortality occurred during the first year following planting in the Agassiz Forest Reserve and early investigations showed that most of this mortality resulted from root damage attributed to the feeding of white grubs, Phyllophaga and Serica spp. (2). Subsequent studies indicated that grub populations could be reduced by furrowing proposed planting sites during the summer of the year preceding planting (3). As furrowing also reduces competition from minor vegetation it has been adopted as standard procedure by the Manitoba Forest Service when trees are to be hand-planted. However, pre-furrowing is not practiced when seedlings are machine-planted in Manitoba as the machines are equipped with scalping plows to remove the sod layer. This reduces competition from minor vegetation but does not give adequate protection against white grub attack. Consequently, investigations of the feasibility of employing chemical control measures with the machineplanting method under Manitoba conditions were commenced in 1963.

\footnotetext{
${ }^{x}$ Contribution No. 1112, Forest Entomology and Pathology Branch, Department of Forestry, Canada.

${ }^{2}$ Forest Entomology Laboratory, Box 6300, Winnipeg 1, Manitoba, Canada.
} 
Shenefelt and others describe insecticide-dispensing apparatus for treating machine-planted red pine seedlings in Wisconsin (7), and report successful results with various insecticides $(4,5,6,8)$. By this method the soil beneath each seedling is spot-treated with approximately $8.5 \mathrm{ml}$ of an emulsion but apparently the volumes delivered are more variable than is desired for experimental work. Attachments have also been developed in the U. S. A. for dispensing granular fertilizer (1), but these are not automatic and require an additional operator. These two devices appear to be the only ones described in the literature, and as neither is completely satisfactory for experimental purposes it was decided to design an applicator that would provide a spot-treatment of seedlings by automatically dispensing measured amounts of either liquid or granular formulations in the furrow beneath the seedling.

\section{Description of AtTachments}

The attachments were mounted on a Lowther tree planter Serial No. ST56175 (Fig. 1). They are operated by a No. 40 roller chain from a 35-tooth sprocket mounted on the hub of the left front wheel (Fig 2, A). The sprocket and chain are protected from below by a 0.25 -inch steel plate welded to the frame of the planter. A 2-inch length of 3-inch pipe coupling is welded between the sprocket and the wheel hub to prevent the chain from rubbing on the tire. The chain drives a 60-tooth sprocket fitted to a 1-inch shaft turning in self-aligning pillow block bearings mounted on a supporting bracket attached to the frame of the machine (Fig. 2, B). The sprocket turns one revolution for every 12 feet of forward motion by the machine when the tires are inflated to 28 pounds. Insecticide is released in the bottom of the planting trench at regular intervals for 1 foot in every 6 feet. A red warning light is mounted on the trenching shoe, where it is readily visible to the operator (Fig. 4, A). It is automatically switched on just prior to each release of chemical to aid the operator in placing the seedlings in the treated strips of soil. The light operates on the tractor battery and is switched on or off by contacts mounted on the side of the cam.

Liquid and granular insecticide formulations are dispensed by separate systems, which are discussed individually.

\section{Liquid dispenser}

Measured quantities of liquid formulations are dispensed by a cam-operated self-filling syringe. The cam was cut from 0.25 -inch steel plate and is welded to the hub of the 60-tooth sprocket. It is bilobed, each lobe having a uniform motion displacement of 1.25 inches during $30^{\circ}$ of revolution (Fig. $2, \mathrm{C})$. The return sides of the lobes have gradual slopes to ensure uniform filling of the syringe. A $10-\mathrm{ml}$ syringe was machined from brass and is fitted with a Cornwall Luer-Lok male adapter to which a two-way valve and catheter tip are attached (Fig. 3, A) 3 . The syringe is operated by the reciprocating motion of a spring-loaded rod following the contours of the cam on a

\footnotetext{
'Cornwall Luer-Lok male adapter No. H1468L, two-way valve No. 470V, and catheter tip No. $470 \mathrm{C}$, manufactured by Becton, Dickinson and Company, Rutherford, N.J.
} 
0.5 -inch diameter roller (Fig. 2, D). The rod is attached to the plunger of the syringe by a short length of 0.5 -inch rubber garden hose clamped in place. The plunger is protected by a length of 1.5-inch plastic hose (Fig. 3, B). The cam-follower rod is kept from turning by a collar with one side flattened, which slides along the support bracket (Fig. 3, C). The bent end of a spring-loaded lever engages this collar and holds the cam-follower off the cam when the dispenser is not in use. A 10-gal drum mounted above the machine serves as the reservoir for the liquid insecticide. Plastic tubing carries the liquid by gravity from the drum to the syringe and thence to the planting shoe where it is discharged (Fig. 4, B).

\section{Granule dispenser}

The granular insecticide is dispensed by a rotating drum assembly (Figs. 3, $D$ and $4, C)$. The drum consisted of a 7-inch flat pulley with its face machined flat and cut to 3 inches in width. Two slots 1 inch in width and 2 inches long were cut into the pulley on diametrically opposite faces. Metal cups of $75 \mathrm{ml}$ capacity were welded into these slots. A 3-inch-wide metal band lined with automobile brake lining material encircles the pulley, with provision for tightening as the lining wears down. A 2-inch square hole was cut through the band and lining at the top and another at the bottom for entrance and discharge of the granules. The pulley is mounted on a 1 -inch shaft supported by pillow block bearings. It is driven by a roller chain from the cam-supporting shaft (Fig. 3, E). A 0.375-inch pin through the pulley shaft engages a notch in a splined sleeve attached to the driving shaft. The pulley is disengaged from the driving shaft, when not in use, by means of a lever attached to the splined sleeve (Figs. 3, F and 4, D). The pulley and band assembly are enclosed in a 16-gauge mild steel case, which is attached to the top of the band by a plate welded around the intake port. A covered hopper made from 0.125 -inch steel plate is mounted above the drum assembly (Fig. 1). The hopper is connected to the intake port of the dispenser by a short length of flexible fabric hose. The lower half of the dispenser case is funnel-shaped and is attached to a length of 1.5-inch rubber hose which carries the granules to the base of the trenching shoe (Fig. 4, E). The hose slides up and down within the shoe when it is lifted or lowered but is prevented from moving backwards by two brackets welded into the shoe.

\section{Discussion}

The operation of the insecticide dispensing attachments was tested in each of three different areas in 1963. Four formulations of insecticides: emulsifiable aldrin, heptachlor, granular aldrin, and toxaphene, were applied at .44 pounds of active ingredient for each 1000 seedlings planted. White grub populations were low in all three areas, and damage caused by them was negligible. Evaluation of the effectiveness of the chemical control has therefore been impossible to date and experiments are continuing. However, the equipment performed satisfactorily with only minor mechanical difficulties, which were readily adjusted or corrected. The operator experienced no difficulty in planting the seedlings in the treated strips of soil. 
Insecticide companies recommend that respirators be worn during the application of potentially dangerous insecticides. However, it is not considered necessary to wear rubber gloves while planting with this machine as the outlet tubes deliver the chemicals at the bottom of the trench and no spilling or splashing occurs.

Recent developments in fertilizers make it possible to apply granular fertilizers at planting time, as some of the newer fertilizers are non-burning and long-lasting (1). Seedling response differs widely according to species and further testing under various conditions is required. The granule dispenser described in this paper is considered especially suitable for this purpose because liquid insecticide can be delivered simultaneously.

Working drawings showing the details of construction of the above equipment are available on request.

\section{ACKNOWLEDGEMENTS}

The authors wish to acknowledge the assistance of the Director and staff of the Manitoba Forest Service, who extended their cooperation and support to this project. Special thanks are due to Mr. Earl Grier of the Whiteshell Provincial Park staff for his assistance in the design and construction of the equipment.

\section{Literature Cited}

1. ANONYMOUS. 1963. Fertilizer attachment for tree-planting machine. Forestry Equipment Notes A. 32.63. Food and Agriculture Organization of the United Nations, Rome, Itzly.

2. PRENTICE, R. M., and V. HILDAHL. 1957. Provinces of Manitoba and Saskatchewan, Forest Insect Survey. In Annual Report of the Forest Insect and Disease Survey, For. Biol. Div., Can. Dept. Agric.

3. - and V. HILDAHL. 1959. Provinces of Manitoba and Saskatchewan, Forest Insect Survey. In Annual Report of the Forest Insect and Disease Survey, For. Biol. Div., Can. Dept. Agric.

4. SHENEFELT, R. D. 1956. A further note on protecting machine transplanted trees from white grubs. Univ. Wisc. For. Research Note No. 25.

5. — and H. G. SIMKOVER, 1950. White grubs in Wisconsin forest tree nurseries. Jour. Forestry 48:428-434.

6. - and H. G. SIMKOVER. 1951. Insecticides for control of white grubs. Jour. Econ. Ent. 44:359-362.

7. - H. R. LIEBIG, and R. C. DOSEN. 1955. Protecting machine transplanted trees from white grubs. Tree Planters' Notes No. 20:14-17.

8. - R. C. ROSEN, and D. W. RENLUND. 1961. What does insecticide treatment for white grub control at time of field transplanting of pine trees mean? Jour. Forestry 59:651-655. 